\title{
Nostalgia y esclavitud en la era de las revoluciones
}

Adrián López Denis

Este ensayo es una reconstrucción del proceso de apropiación discursiva que el cirujano español Francisco Barrera y Domingo utilizó para producir su estudio sobre la nostalgia de los esclavos en la Cuba del siglo dieciocho.

Palabras clave: Nostalgia, ilustración, esclavitud, discurso 
El tratado más voluminoso y detallado sobre las enfermedades de los esclavos en el mundo atlántico fue escrito en la Habana a finales del siglo dieciocho. Su autor, el cirujano aragonés Francisco Barrera y Domingo, resumió en este fascinante manuscrito las experiencias acumuladas durante casi dos décadas de práctica ininterrumpida en las plantaciones del Caribe. Aunque había sido completado en Julio de 1798, el documento original no fue descubierto hasta 1910, cuando el anticuario Manuel Pérez Beato lo adquirió como parte de una remesa de manuscritos sobre la historia colonial de Cuba. En 1953, las investigadoras Lydia Cabrera y María Teresa de Rojas publicaron en la Habana la única edición conocida del libro de Barrera. Como esa tirada original fue bastante limitada y su distribución fuera de la isla ha sido mínima, este importante tratado permanece relativamente poco estudiado. ${ }^{1}$

El título completo de la obra nos permite ubicarla de inmediato en una cartografía conceptual definida por la superposición meticulosa de vectores geográficos, ideológicos, disciplinarios y patológicos (Figura 1).

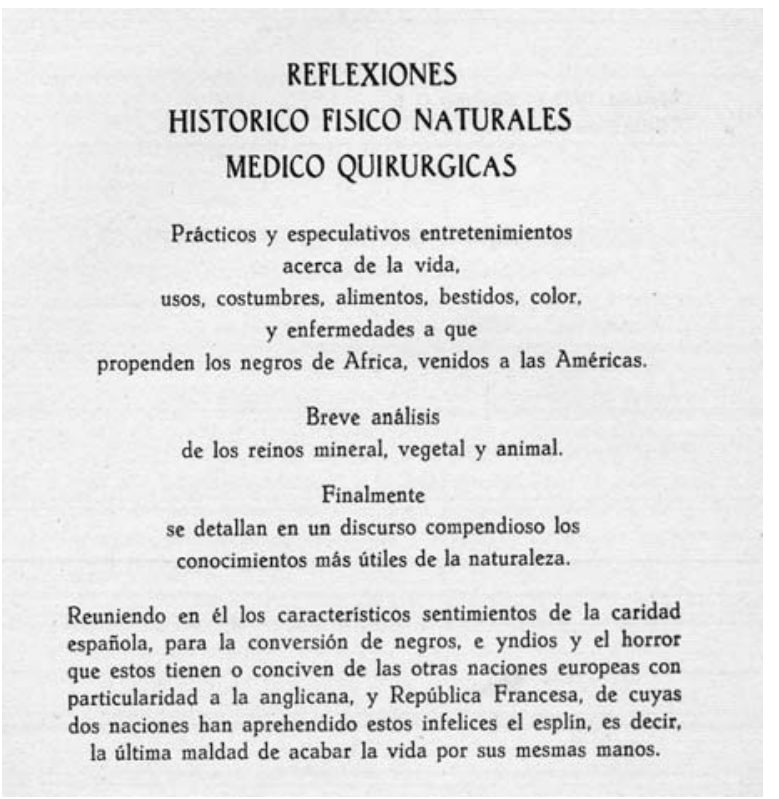

Figura 1

1. Para una discusión más detallada sobre la vida y la obra de Francisco Barrera y Domingo véase López Denis (2005). Agradezco a Ana María Galdini Raimundo Oda que me halla invitado a darle un nuevo giro al argumento central de ese ensayo.

Rev. Latinoam. Psicopat. Fund., São Paulo, v. 11, n. 4, p. 779-790, dezembro 2008 (Suplemento) 
Este es un texto que se presenta a sí mismo mediante un inventario concienzudo de obsesiones transatlánticas. En sus páginas se entrelazan lo político y lo natural a lo largo de trayectorias establecidas mediante la circulación de ideas, esclavos, y mercancías. Los negros de África venidos a las Américas protagonizan este drama intelectual donde la administración del saber y la reproducción de la utilidad constituyen dos caras de una misma moneda ilustrada. Las Reflexiones de Barrera documentan la aparición de un nuevo modelo plantacionista en el Caribe hispano, basado en el trabajo intensivo y la lógica fabril. El título establece una relación directa entre la cultura anglicana, el republicanismo francés y el suicidio de esclavos porque Barrera percibe la realidad del mundo atlántico en términos eminentemente geopolíticos. Desde su punto de vista, esta versión antillana del esplín tiene su origen en las tensiones generadas por la explosión productiva del azúcar en las llanuras habaneras. Operando bajo la influencia de ideales foráneos, los esclavistas criollos han implantado un modelo ideológico-productivo que arrasará con la supuesta generosidad caballeresca española, imponiendo en su lugar los ideales implacables de la modernidad industrial del norte europeo.

¿Cuáles son las referencias que informan el universo ideológico y científico de Francisco Barrera y Domingo? ¿De dónde nace la vocación crítica que vertebra este texto extraordinario? En una de las secciones iniciales de la obra, el cirujano español dedica varias páginas al análisis de la nostalgia (Barrera, 1953, p. 64-75 [1798]). Desde su punto de vista, los esclavos recién llegados de África eran especialmente vulnerables a los estragos de esa dolencia singular. En este ensayo pretendemos reconstruir el proceso mediante el cual Barrera llegó a esta novedosa conclusión, poniendo nuestro énfasis en las implicaciones políticas de su metodología y en el sentido último de la nostalgia como diagnóstico. Como nuestro objetivo es ilustrar más que demonstrar, hemos decidido incluir un facsímil del pasaje original al final de nuestro texto. Las referencias en negritas indican páginas específicas dentro de este fragmento que reproducimos.

Barrera comienza su discusión sobre la nostalgia con una Advertencia donde deja claramente establecidas sus prioridades como patriota y como profesional (Barrera, 1953, p. 64, [1798]). El hecho de que se incluya aquí una referencia directa al título mismo del tratado sugiere que nos encontramos ante un pasaje clave. Este es el manifiesto intelectual y político de Francisco Barrera. El autor nos asegura que ha extraído su saber de su experiencia. Aunque su origen humilde y su posición marginal lo limitan, este cirujano trasplantado de las montañas de Aragón a las plantaciones azucareras del Caribe está dispuesto a defenderse. Barrera cree en la importancia última de su misión como médico de esclavos. Su trabajo lo redime, tanto desde el punto de vista profesional como moral. Sus críticos lo desprecian, pero él está dispuesto a ignorarlos. No hay dudas de que el autor quiere abrir esta sección con una clara afirmación de su individualidad. 
Sin embargo, una lectura más cuidadosa de este pasaje nos revela niveles de complejidad insospechados. En 1731, el médico y naturalista suizo Johann Jakob Scheuchzer había publicado un famoso ensayo sobre la nostalgia que comenzaba así:

Ad id magis magisque me applico, ut inquisitiones meas Historico Naturales, quibus immergor, usui Societatis Humanae, \& Patriae cumprimis accomodem. Ita nonin curiositate mera subsisto, sed a Theoria ad Praxim tendo. Ita scrupulos eximere tento iis, qui persuasum sibi habent, tot, quos suscipo labores, impensas tot, sudores tot, quibus dissluo, career omni utilitate, virgula me perstringut nontam censoria, quam satyrica, objiciendo Persiamum illud O curas Hominum? O quantum est in rebus inane? (Scheuchzer, 1731, p. 307)

Es evidente que Barrera se ha apropiado de este párrafo introductorio, intercalando apenas unas pocas frases para reajustar el sentido del texto original, de manera que se acomode a las exigencias expresivas del contesto caribeño en el que escribe. Este ensayo de Scheuchzer lo ha impresionado tanto que el cirujano español ha decidido adoptar la persona misma del científico suizo. ¿Cómo acercarnos a la obra de un autor que utiliza este tipo de estrategia retórica? ¿A qué se refiere Barrera cuando habla de su patria, de sus "Ynquisiciones", sus empresas, sus trabajos y sus sudores? ¿Son estos términos el resultado de un proceso mecánico de traducción? ¿Estamos frente a un simple caso de plagio?

Para responder estas preguntas necesitamos analizar más profundamente la genealogía de la nostalgia como diagnóstico. El ensayo de Scheuchzer ocupa un lugar muy importante en esa historia. Desde su punto de vista la nostalgia no provenía de alteraciones en la imaginación del paciente, sino de cambios en su entorno. Barrera está empeñado en probar que las enfermedades que sufren los esclavos durante su viaje de África a las Américas son un resultado de la falta de libertad (Barrera 1953, p. 65, [1798]). La explicación propuesta por Scheuchzer convierte a la nostalgia en una dolencia provocada por acciones externas sobre el cuerpo y la mente del enfermo. Barrera quiere convencer a sus lectores de que la esclavitud misma es la causa de todos los males que sufren los esclavos. Si sus pacientes han caído víctimas de la nostalgia es porque se les ha sacado violentamente de un ambiente al cual se hallaban bien adaptados, forzándolos a vivir en una atmósfera deletérea.

Scheuchzer había escrito su ensayo como una respuesta patriótica a las opiniones que sobre esta enfermedad prevalecían en la Europa del barroco. La descripción original de la nostalgia había sido publicada en 1678 por un estudiante de medicina suizo llamado Johannes Hofer. Este jovenzuelo había dedicado su tesis al estudio de la tristeza profunda que afectaba a algunos soldados cuando servían fuera de la patria. Desde su punto de vista, la dolencia era tan específica 
que merecía tener un nombre propio. Siguiendo la lógica académica europea del momento, Hofer había creado el término nostalgia mediante una yuxtaposición de las palabras griegas nostos (regreso) y algios (dolor). Así fue como la dolorosa necesidad de regresar a la patria entró en el catálogo de las enfermedades propias de los militares. La palabra nostalgia había iniciado la tortuosa marcha que la llevaría de los márgenes semánticos de la fisiología barroca al centro del vocabulario crítico-literario del occidente moderno.

En su tesis, Hofer había propuesto un mecanismo fisiológico muy concreto para explicar las causas de este mal. Desde su punto de vista, un desorden de la imaginación provocaba que el fluido circulando a lo largo de los nervios pasase una y otra vez por la zona del cerebro responsable del deseo de regresar a la patria. Una vez que esta preferencia circulatoria quedaba establecida, cada nuevo flujo venía a reforzarla. Todo lo que se relacionaba con la idea del hogar tendía a multiplicarse, el resto de las ideas y de las percepciones se debilitaban. El paciente se tornaba indiferente hacia la mayoría de los estímulos y se encerraba en un mundo interior repleto de memorias. Al estado melancólico resultante le seguía una languidez generalizada. El nostálgico perdía el apetito, dejaba de hablar, se postraba en su lecho y terminaba muriendo de inanición. La única cura posible era el regreso a la patria. Hofer creía que los adolescentes suizos eran especialmente susceptibles a este mal porque habían crecido en el aislamiento relativo de los valles alpinos, ajenos a la vertiginosa marcha de la vida mercantil europea que comenzaba a despuntar a finales del siglo diecisiete.

Scheuchzer, en su ensayo, rechazó la idea de que la imaginación provinciana de los soldados suizos los hacía particularmente vulnerables a los ataques de una dolencia tan grave como la nostalgia. Decidido a mantener incólume el prestigio bélico de sus compatriotas, este autor propuso una explicación iatromecánica de las causas de la enfermedad. Para él, la nostalgia era simplemente el resultado de un cambio brusco de presión atmosférica que afectaba la distribución de fluidos vitales en el cuerpo de los soldados cuando bajaban de los Alpes a las llanuras del centro de Europa. La mentalidad de los jóvenes suizos no tenía nada de particular, eran sus corazones los que sufrían por el exceso de presión a que se encontraban de repente sometidos. Desde el punto de vista de Scheuchzer, los pacientes aquejados de nostalgia podían curarse con una dieta rica en alimentos ligeros, propios de regiones altas, o con unas breves vacaciones en la cima de la más próxima colina (Starobinski, 1966, p. 87-89).

Estos nostálgicos de Scheuchzer, con sus corazones literalmente oprimidos, ofrecen a Francisco Barrera un pretexto excelente para criticar la esclavitud. Veamos como se las arregla para construir su argumento, trasladando (¿traduciendo?) la lógica iatromecánica del científico suizo al contexto colonial 
y tropical del Caribe (Barrera, 1953, p. 66 [1798]). Por razones obvias, la presión atmosférica no puede jugar un papel exclusivo en el discurso del cirujano español. En lugar de explicar la nostalgia como el resultado de un simple cambio de altitud, Barrera se basa en lo que podríamos llamar un descenso de las cimas del placer a los abismos del dolor (la mutación de un país de delicias, a la extrechez de un barco mercante). Para él, este gradiente es tan real como el que existe entre las montañas y los llanos. Las consecuencias del tráfico de esclavos sobre la economía animal son tan claramente mensurables como los cambios mismos del barómetro.

Por supuesto, África sólo puede ser considerado un país de delicias si los africanos tienen la capacidad necesaria para apreciar estos placeres. Barrera admite que los nativos del continente no pueden disfrutar de su entorno de la misma manera racional con que los filósofos europeos disfrutan del suyo (Barrera 1953, p. 66 [1798]). Esta idea suya estaba bastante extendida entre los naturalistas de la época. Por ejemplo, el Conde de Buffon, en su famosa Historia Natural, tiene una referencia que resuena de manera directa con este pasaje del cirujano español. Refiriéndose a "los negros de Guinea y Sierra Leona”, dice Buffon:²

A menudo viven en lugares salvajes y desolados, a pesar de que en la vecindad existen ricos valles, colinas cubiertas de árboles, o campos verdes y fértiles cruzados, de la manera más agradable, por ríos y arroyos. Pero su indolencia y su estupidez los hacen insensibles a los placeres de esta naturaleza. (1781, p. 145-146)

Barrera, sin embargo, no cree que los habitantes de África sean totalmente incapaces de percibir y apreciar la belleza del ambiente que los rodea. Desde su punto de vista, estas supuestas limitaciones intelectuales no se extienden al mundo de las percepciones y los sentimientos. Para Barrera el africano posee una inocencia que le permite disfrutar de los placeres naturales con una intensidad incluso mayor que la de los europeos. Llega a sugerir que sus propios compatriotas serían más saludables si trocasen el ilusorio mundo de los placeres efímeros que engendra la civilización por la felicidad más duradera que nace de la apreciación inocente de la naturaleza.

Esas ideas suyas no eran nada novedosas. Los ilustrados europeos solían celebrar la inocencia y la potencia vital de nativos y salvajes con el mismo entusiasmo con el que desdeñaban su capacidad de raciocinio. El propio Buffon, en esta misma sección del volumen que venimos citando, había basado su

2. Las traducciones de Buffon y de Raynal son de Adrián López Denis.

Rev. Latinoam. Psicopat. Fund., São Paulo, v. 11, n. 4, p. 779-790, dezembro 2008 (Suplemento) 
caracterización de los africanos en opiniones de este tipo, publicadas por el viajero jesuita Pierre François Xavier de Charlevoix (1731):

Él [Charlevoix] añade que el genio de todos los negros de Guinea es extremadamente limitado; que algunos de ellos son perfectamente estúpidos, no siendo capaces de contar más allá del número tres; que nunca piensan de manera espontánea; que no tienen memoria; que tanto el pasado como el futuro les son desconocidos; que los más despiertos entre ellos tienen cierto humor y son capaces de imitar expresiones faciales ajenas; que son muy astutos, y prefieren dar la vida que revelar un secreto; que en general son gentiles, humanos, dóciles, simples, crédulos, y supersticiosos; y que son fieles, y valientes, y que con la disciplina apropiada podrían ser excelentes soldados. Aunque los negros tienen poco genio, sus sentimientos son extremadamente agudos. De acuerdo a la manera en que se les trata ellos son alegres o melancólicos, trabajadores u holgazanes, amigos, o enemigos. Cuando se les alimenta bien y no se les maltrata se mantienen contentos, gozosos, listos para cualquier tarea, y la satisfacción de sus mentes se hace patente en sus semblantes. Pero cuando se les oprime o se abusa de ellos se ponen tristes y a menudo mueren de melancolía. Son tan sensibles a los beneficios como a los abusos, y son capaces de sentir un odio mortal contra quienes los ofenden. Por otro lado, cuando sienten afecto hacia su amo no hay tarea, por peligrosa que sea, que no estén dispuestos a ejecutar con valor para demostrar su celo y su fidelidad. Son por naturaleza cariñosos, y sienten un amor ardiente hacia sus hijos, amigos, y compatriotas. Lo poco que poseen están dispuestos a distribuirlo libremente entre los necesitados, sin otro motivo que la pura compasión que sienten hacia los indigentes. (Buffon, 1781, p. 151-152)

Es obvio que Barrera conoce muy bien este libro de Buffon, el cual cita con frecuencia a lo largo de las Reflexiones (Barrera, 1953, p. 216, 235, 236, 239, 304, [1798]). También parece haber leído directamente L'Histoire de l'Isle Espagnole ou de Saint-Domingue, escrita por Charlevoix (Barrera 1953, p. 34, [1798]). Como veremos, es posible detectar ecos de la retórica empleada por Buffon y Charlevoix en la caracterización que hace Barrera del carácter de los esclavos caribeños. Sin embargo, varios elementos en este pasaje serán reinterpretados por el cirujano español de manera radical. Aunque incluye una lista bastante similar de caracteres antagónicos para describir a los africanos, no los generaliza a la comunidad entera ni los usa como evidencia de una supuesta inconsistencia moral. Desde su punto de vista, no todos los esclavos poseen las mismas "inclinaciones", y es precisamente esta heterogeneidad lo que los hace semejantes a cualquier otro grupo de seres humanos:

Las inclinaciones naturales en los negros, son lo mesmo que las demás naciones, ésto es, que unos negros, son algo más prudentes que otros; unos ay 
temerarios, otros belicosos y guerreros, otros pusilánimes, unos muy vivos y que con facilidad aprenden qualquiera arte, otros stólidos en sumo grado, otros hablan con mucha facilidad y aprenden con vrebedad qualquiera edioma, otros ni un hablar saben, unos aprenden luego a ser racionales, otros al contra, quanto más tratan con los europeos, más bestiales son; ay algunos que los capolaran primero, que rebelar un secreto, otros son muy disimulados, pero mentirosos; otros son beraces; unos muy trabajadores, otros olgazanes y perezosos; unos ay que aunque se despedazen a puñaladas sus mayores amigos, en nada se conturban; otros ay pacificificos, hospitalarios y misericordiosos, con sus amigos y enemigos. Y en fin, en una palabra, quantas inclinaciones tienen los hombres civilizados, tantas tienen ellos sin civilizar. (Barrera, 1953, p. 54-55, [1798])

Para explicar las causas de la nostalgia de los esclavos, Barrera combina un argumento biomédico con un principio político. De Scheuchzer toma la idea de que los cambios ambientales tienen consecuencias fisiológicas en todos los individuos, independiente de su personalidad. De Buffon y Charlevoix extrapola la noción de que el maltrato de los esclavos genera melancolía. En el lugar de un simple cambio de presiones propone como causa primera de la nostalgia una transformación más amplia en el universo de relaciones sociales que gobierna la vida de los africanos. Esto le permitirá extraer conclusiones muy radicales a partir de premisas relativamente inocuas.

Entre los autores que el cirujano español identifica como pioneros en el estudio de la nostalgia se encuentran Scheuchzer y William Buchan (Barrera, 1953, p. 68, [1798]). Como hemos visto, Barrera reproduce a Scheuchzer sin citarlo, y esta claro que conoce muy bien su ensayo. El caso de Buchan es un tanto más complejo. Aunque revisamos varias ediciones inglesas y norteamericanas de su famosa Medicina doméstica, fuimos incapaces de encontrar la referencia que menciona nuestro cirujano. Finalmente, en la primera edición francesa de la obra encontramos una nota al pie, en el capítulo dedicado a la melancolía, donde se describe muy superficialmente la nostalgia, o maladie du pays (Buchan, 1776, p. 331-332). Aparentemente, Barrera consultó la Medicina Doméstica en una traducción al español basada en esta edición francesa. Sin embargo, hasta donde hemos podido comprobar, ni Scheuchzer ni Buchan describen a la nostalgia como una dolencia que puede conducir a la muerta voluntaria del paciente. ¿En que se basa nuestro autor para afirmar que los esclavos recién llegados de África están predispuestos al suicidio? Barrera (1953, p. 69, [1798]) dice que estos individuos se privan de la existencia inspirados por la idea de que después de muertos regresarán a su patria, liberándose así de la opresión impuesta por los europeos. ¿Cuáles son las fuentes de esta noción tan específica? ¿De donde ha salido esta idea?

Rev. Latinoam. Psicopat. Fund., São Paulo, v. 11, n. 4, p. 779-790, dezembro 2008 (Suplemento) 
Veamos lo que dice el padre Raynal sobre el suicidio de esclavos en su famosa Histoire philosophique et politique des établissemens et du commerce des Européens dans les deux Indes:

Hay bárbaros que, considerando la piedad como una muestra de debilidad, mantienen el látigo de la tiranía siempre levantado. Gracias al cielo, la negligencia, la infidelidad, la deserción y el suicidio de las víctimas de su codicia les sirve a estos amos de castigo. Puede verse a varios de esos desafortunados, especialmente los de nación Mina, terminar dignamente sus vidas, persuadidos de que después de muertos renacerán en su patria, a la que consideran el país más bello del mundo. El espíritu de venganza les proporciona a otros recursos mucho más destructores. Instruidos desde la infancia en el arte de los venenos que nacen, por así decirlo, de sus manos, ellos los utilizan para matar los bueyes, los caballos, las mulas, sus propios compañeros de esclavitud, todos los seres que sirven para poner a producir las tierras de sus opresores. Para alejar de ellos las sospechas, ensayan sus crueldades sobre sus propias mujeres, sus hijos, sus amantes, sobre todo lo que consideran más valioso. Ellos saborean, en este proyecto aterrador y desesperado, el doble placer de librar a su especie de un destino más horrible que la muerte, y de dejar a sus tiranos en un estado de miseria que los acerca al suyo propio. (Raynal, 1774, p. 201-202)

El título mismo de las Reflexiones incluye una referencia directa al suicidio de los esclavos, y a lo largo de su tratado Barrera le dedica muchísima atención a este tema. Sin embargo, cuando Barrera se refiere al suicidio como una forma de resistencia, y a la repatriación después de la muerte como una fuente de consuelo, los términos que utiliza y la lógica de su discurso son prácticamente idénticos a los del padre Raynal:

... se puede decir que todo su carácter y opiniones, la forman en mucha parte sus amos propios; si éstos los aman y tratan con cariño, corresponden hasta el heroísmo; pero si son demasiado rígidos, saben sufrir y disimular sus sentimientos, hasta tener ocasión de bengarse, lo que executan con venenos, empleándolos en los ganados, en los otros esclabos, y en sus amos propios, y domésticos, y en quanto es útil a su enemigo. Con especial los de la costa de Mina, que hacen quanto llebo dicho, hasta quitarse desesperadamente la vida, persuadidos que van a renacer á su Patria, que tienen por el mejor país del mundo. (Barrera, 1953, p. 41 [1798])

Este breve pasaje tiene dos componentes centrales, y cada uno de ellos se deriva de fuentes diferentes. La idea de que los amos son responsables por el comportamiento y las inclinaciones de sus esclavos nace de Buffon y Charlevoix ("De acuerdo a la manera en que se les trata ellos son alegres o melancólicos, trabajadores u holgazanes, amigos, o enemigos”). La segunda mitad del párrafo se basa claramente en el texto de Raynal. Gracias a una referencia incluida en

Rev. Latinoam. Psicopat. Fund., São Paulo, v. 11, n. 4, p. 779-790, dezembro 2008 (Suplemento) 
otra sección de las Reflexiones, es posible constatar que nuestro autor tenía acceso al libro de Raynal (Barrera, 1953, p. 27 [1798]). La manera en que Barrera construye su argumento, hilvanando fragmentos de textos disímiles, tienen mucho que ver con la estrategia utilizada para crear libros tales como la propia Histoire des les deux Indes. Aunque esta obra incendiaria se asocia con la figura de Guillaume-Thomas-François Raynal, sabemos que en realidad fue el resultado de un proceso de creación colectiva. Colaboraciones originales o textos reciclados de una docena de autores, incluyendo a Diderot, D’Holbach y Buffon, vinieron a formar parte de la Histoire (Aravamudan, 1993). Podemos decir que Barrera forma parte del mismo universo en el cual se mueven todos los autores a los cuales “copia”, precisamente porque el cirujano español no sólo repite sus palabras sino que participa, como un “copista” más, en la creación colectiva del lenguaje mismo de la ilustración.

Es este mecanismo de yuxtaposición y síntesis legitimado por sus contemporáneos lo que le permite a Barrera combinar fisiología y política con tanta naturalidad. Desde su punto de vista el acto mismo de esclavizar a los africanos es patogénico. Los traficantes los arrancan de su Patria y los separan de sus seres queridos, alterando su dieta, sus vestidos, sus costumbres y hasta el aire que respiran (Barrera 1953, p. 70-71, [1798]). Esta es una transformación mucho más radical que la experimentada por los soldados suizos al bajar de los Alpes. Quizá la diferencia de presión atmosférica entre las costas de África y las del Caribe no sea tan marcada, pero el efecto combinado del pequeños cambios barométricos y grandes alteraciones morales es suficiente para provocar la nostalgia de los esclavos. ${ }^{3}$

El carácter aditivo de la nostalgia como enfermedad explica también porqué algunos esclavos sufren sus efectos de manera más marcada. Lo que distingue a los nostálgicos del resto de sus compañeros es la especificidad biográfica misma que determina la identidad de cada individuo. Es por eso que Barrera (1953, p. 74, [1798]) recomienda a sus colegas que reconstruyan la trayectoria vital de

3. Al describir los síntomas de la nostalgia, Barrera (1953, p. 72-73, [1798]) se refiere a una fuente que identifica como "Hande No TH. 9.” El texto de este pasaje se corresponde de manera bastante clara con la caracterización original de la enfermedad, tal y como aparece en la tesis de Johanes Hofer. En el ensayo de Scheuchzer (1731, p. 307-308) se reproduce esa sección de la tesis de Hofer, identificada como "Harderus Th. IX”. En esto seguía Scheuchzer la convención académica de la época, en la cual las tesis se identificaban mediante números consecutivos asociados al apellido del tutor, que en este caso se llamaba Johannes Jakob Harder. Un error de Barrera, o de quienes trascribieron su manuscrito, hizo que la frase "Harderus Th. IX” apareciese como "Hande No TH. 9".

Rev. Latinoam. Psicopat. Fund., São Paulo, v. 11, n. 4, p. 779-790, dezembro 2008 (Suplemento) 
cada uno de sus pacientes, mediante un cuestionario detallado, utilizando a otro esclavo como intérprete. Al proponer semejante estrategia como punto de partida para establecer el rumbo que debe seguir la terapéutica de la nostalgia, el cirujano español estará abriendo un camino novedoso en la práctica psiquiátrica ilustrada. A este tema fascinante dedicaremos otro trabajo en el futuro.

\section{Referencias}

Aravamudan, S. Trop(icaliz)ing the Enlightenment. Diacritics, v. 23, n. 3, p. 48-68, 1993. Barrera y Domingo, F. Reflexiones Historico Fisico Naturales Medico Quirurgicas: practicos y especulativos entretenimientos acerca de la vida, usos, costumbres, alimentos, bestidos, color, y enfermedades a que propenden los negros de Africa, venidos a las Américas. Breve análisis de los reinos mineral, vegetal y animal. Finalmente se detallan en un discurso compendioso los conocimientos mas útiles de la naturaleza. Reuniendo en él los característicos sentimientos de la caridad española, para la conversion de negros, e yndios y el horror que estos tienen o conciven de las otras naciones europeas con particular de la anglicana, y República Francesa, de cuyas dos naciones han aprehendido estos infelices el esplín, es decir, la última maldad de acabar la vida por sus mesmas manos. Livro Segundo y Período Segundo, Comenta esta obra, con varias adiciones y enfermedades nuevas, para vien de la humanidad. el Licenciado Francisco Barrera y Domingo. Havana, 23 de Julio de el año 1798. La Habana: Ediciones C. R., 1953.

Buchan, G. Médecine domestique ou traité complet des moyens de se conserver en santé, vol III. Edimbourg, Paris: Chez G.. Desprez, 1776.

Buffon, G. L. L., comte de. Natural History, General and Particular, vol. III. London and Edinburgh: Printed for W. Strahan and T. Cadell; W. Creech, 1781.

Charlevoix, P. F. X. de. Histoire de l'Isle espagnole ou de Saint Domingue. Paris: Jacques Guerin, 1731.

López Denis, A. Melancholia, Slavery, and Racial Pathology in Eighteenth-Century Cuba. Science in Context, v. 18, n. 2, p. 179-200, 2005.

RaynaL, G. T. F. Histoire philosophique et politique des établissemens et du commerce des Européens dans les deux Indes, v. IV. La Haye: Chez Gosse Fils, 1774.

Scheuchzer, J. J. De Nostalgia. De Bononiensi Scientiarum et Artium Instituto atque Academia Commentarii, v. I, p. 307-33, 1731.

Starobinski, J. The Idea of Nostalgia. Diogenes, n. 14, p. 81-103, 1966. 


\section{Resumens}

(Nostalgia e escravidão na era das revoluções)

Este ensaio é uma reconstrução do processo de apropriação discursiva que o cirurgião espanhol Francisco Barrera y Domingo utilizou para produzir seu estudo sobre a nostalgia dos escravos em Cuba do século dezoito.

Palavras-chave: Nostalgia, ilustração, escravidão, discurso

(Nostalgie et esclavage à l'époque des révolutions)

Cet essai est une reconstruction du processus d'appropriation discursive que le chirurgien espagnol Francisco Barrera y Domingo utilisa pour produire son étude sur la nostalgie des esclaves à Cuba au dix-huitième siècle.

Mots clés: Nostalgie, illustration, esclavage, discours

(Nostalgia and slavery during the age of revolutions)

This essay is a reconstruction of the process of discursive appropriation that Spanish surgeon Francisco Barrera y Domingo used to produce his study on slave nostalgia in $18^{\text {th }}$ century Cuba.

Key words: Nostalgia, enlightenment, slavery, discourse

Versão inicial recebida em junho de 2008

Versão aprovada para publicação em outubro de 2008

\section{Adrián López Denis}

Historiador; Máster en Economía (1998) y en Estudios Latinoamericanos (2000) por la Universidad de La Habana; Doctor en Historia por la Universidad de California en Los Ángeles (2007). Actualmente participa en un programa de Postdoctorado en Humanidades de la Universidad de Brown. Está escribiendo un libro sobre las relaciones entre la esclavitud, la medicina y la revolución industrial en el mundo Atlántico.

Brown University

Box N, Providence, RI, 02912

e-mail: Adrian_Lopez-Denis@brown.edu 